\title{
HIV-1 Tat alters neuronal intrinsic excitability
}

\author{
Walter Francesconi ${ }^{2,3^{*}}$, Fulvia Berton ${ }^{2,3}$ and Maria Cecilia G. Marcondes ${ }^{1,3^{*}}$ (B)
}

\begin{abstract}
Objective: In HIV+ individuals, the virus enters the central nervous system and invades innate immune cells, producing important changes that result in neurological deficits. We aimed to determine whether HIV plays a direct role in neuronal excitability. Of the HIV peptides, Tat is secreted and acts in other cells. In order to examine whether the HIV Tat can modify neuronal excitability, we exposed primary murine hippocampal neurons to that peptide, and tested its effects on the intrinsic membrane properties, 4 and $24 \mathrm{~h}$ after exposure.

Results: The exposure of hippocampal pyramidal neurons to Tat for $4 \mathrm{~h}$ did not alter intrinsic membrane properties. However, we found a strong increase in intrinsic excitability, characterized by increase of the slope (Gain) of the inputoutput function, in cells treated with Tat for $24 \mathrm{~h}$. Nevertheless, Tat treatment for $24 \mathrm{~h}$ did not alter the resting membrane potential, input resistance, rheobase and action potential threshold. Thus, neuronal adaptability to Tat exposure for $24 \mathrm{~h}$ is not applicable to basic neuronal properties. A restricted but significant effect on coupling the inputs to the outputs may have implications to our knowledge of Tat biophysical firing capability, and its involvement in neuronal hyperexcitability in neuroHIV.
\end{abstract}

Keywords: neuroHIV, HIV Tat, Hippocampal neurons, Electrophysiology, Synaptic transmission

\section{Introduction}

Neuronal plasticity and regeneration are interrelated phenomena, tightly dependent on the normal functioning of the Central Nervous System (CNS). Changes in glia drastically affect neuronal capacity to recover and rewire [1-3]. Microglia invade the CNS at prenatal stages, increasing density during the first weeks of postnatal life, reaching a maximum by P18, concomitant to an intense synaptogenesis period [4-6]. Microglia express cytokines, neurotrophins $[7,8]$, glutamate and NO [9-12], which regulate synaptic properties. Importantly, microglia are critical during Human Immunodeficiency Virus (HIV) infection, because they get infected

\footnotetext{
*Correspondence: wfranc@uic.edu; cmarcondes@SDBRI.org

${ }^{1}$ San Diego Biomedical Research Institute, 10865 Road to the Cure, San Diego, CA 92121, USA

${ }^{2}$ Department of Anatomy and Cell Biology, College of Medicine, University of Illinois Chicago, 6068 COMRB MC 512, Chicago, IL 60612, USA

Full list of author information is available at the end of the article
}

by virus carried into the brain by macrophages at early time points $[13,14]$.

The consequences of HIV in the brain include high incidence of neurological dysfunctions, even in the post-antiretroviral age [14]. Of all HIV-1 peptides, Tat is involved in viral transcription, and is unconventionally secreted by infected targets [15-18], with consequences to neighboring cells, including neurons. HIV-Tat has been linked to impaired learning and memory, and gray matter deficits $[19,20]$, suggesting its involvement in the development of HIV-associated neurological disorders (HAND).

The hippocampus is a brain region involved in cognition, and memory formation, organization, and retrieval, where the main cell type is the excitatory glutamatergic pyramidal neuron, integrating spatial, contextual, and emotional information, while transmitting all outputs to cellular targets throughout the brain, in response to glutamate, a key neurotransmitter [21]. Pyramidal cells in the CA1 and subiculum regions carry output by firing individual or high 
frequency bursts of action potentials (AP), increasing synaptic communication through evoking a postsynaptic spike [22, 23]. They also participate in plasticity and place field development $[24,25]$. Excitatory synaptic transmission in hippocampal neurons is susceptible to changes, contributing to cognitive impairments. Due to the abundance of these neurons, the hippocampus is crucial for recalling when and where an event occurred, or 'episodic memory' [26], one of the first functions lost in HAND and in aging [27, 28]. Importantly, we have demonstrated that HIV Tat prevents long-term potentiation in the hippocampal CA1 region [29]. Our goal was to further characterize the neuronal response to HIV Tat in primary cultures.

Neuronal membrane properties are characterized by means of the input-output response function, giving the rate of AP discharge as a function of the injected current strength. The linear relationship between neuronal input and output is defined by the rheobase (minimum synaptic input that generates an AP), and by the slope (gain). The gain control is a central feature of neural information processing [30]. Changes in gain control, associated with alterations in the conductance of voltage-gated channels such as the A-type (IA), the delayed-rectifier $\mathrm{K}+$ (Id) and L-type voltagegated $\mathrm{Ca}^{2+}(\mathrm{IKCa})$ channels, are critical in several pathophysiological conditions. An increase in IA, Id and IKCa reduces neuronal gain. In contrast, increases in the slow voltage-gated $\mathrm{Ca}^{2+}$ channel conductance (GCaS) increase neuronal gain. The hyperpolarization-activated inward channel (Ih) is 'gain neutral'. The functional relevance of such changes include protecting neurons from over-excitation during ischemia, infection, or aging, and for making neurons more excitable during associative learning [31-36].

We used the slope of the fitted linear function (gain, I-O slope) as a quantitative measure of biophysical firing capabilities under DC step stimulation [37], to examine whether HIV-1 Tat can modulate hippocampal neuron properties, explaining changes in memory functions experienced by HIV+ subjects. In neuronal primary cultures we modeled Tat exposure, and tested its effects on excitability.

In cell line studies, Tat internalization by neurons was detected at $4 \mathrm{~h}$ [38]. Effects on molecular functions and morphology were detected at $24 \mathrm{~h}[39,40]$, preceding neurotoxicity at $48 \mathrm{~h}$ [38]. The ability of Tat to modify neuronal excitability in the primary hippocampal neuron culture system was tested on whole cell patch electrophysiological testing paradigms, at 4 and 24-h time points. We found a significant effect of Tat at $24 \mathrm{~h}$ after exposure.

\section{Main text \\ Methods \\ Hippocampal cultures}

Animal use was approved by Institutional Animal Care and Use Committees of The Scripps Research Institute (TSRI) and San Diego Biomedical Research Institute. In three independent experiments, two pregnant C57Bl/6 females, 5-8 weeks old, were purchased from TSRI Department of Animal Resources. E17 pups [41] ( 7/ experiment) were sacrificed by $\mathrm{CO}_{2}$ inhalation. Hippocampi were dissected in $\mathrm{Ca}^{2+} / \mathrm{Mg}^{2+}$-free, HEPESbuffered Hank's balanced salt solution (HBSS), pH7.45, dissociated through flame-narrowed Pasteur pipettes of decreasing aperture, and resuspended in DMEM without glutamine, $10 \%$ fetal bovine serum and penicillin/streptomycin $(100 \mathrm{U} / \mathrm{ml}$ and $100 \mu \mathrm{g} / \mathrm{ml}$, respectively). Cells were plated (120,000/dish) onto $25 \mathrm{~mm}$ round Matrigel (200 $\mu \mathrm{l}, 0.2 \mathrm{mg} / \mathrm{ml}$; BD Biosciences) pre-coated cover glass glued to cover a 19 -mm-diameter opening drilled through the bottom of a $35 \mathrm{~mm}$ Petri dish. Neurons were grown in $10 \% \mathrm{CO}_{2}$, at $37{ }^{\circ} \mathrm{C}$, and fed on days 1 and 6 , by exchanging $75 \%$ of the media with DMEM containing $10 \%$ horse serum and penicillin/streptomycin. In all experiments, pyramidal-shaped neurons behaved as such in patch-clamp.

\section{Tat stimulation}

Recombinant HIV-1 Tat (Clade B) was from the National Institutes of Health AIDS Research and Reference Reagent Program, Division of AIDS, National Institute of Allergy and Infectious Diseases. In control experiments, Tat was heat-inactivated at $85{ }^{\circ} \mathrm{C}$ for $30 \mathrm{~min}$. The cells were incubated with Tat $10 \mathrm{ng} / \mathrm{ml}(6.4 \mathrm{nM})$. Tat (or inactivated Tat) was added to the media 4 or $24 \mathrm{~h}$ prior to recordings. Coded cultures were removed from $37{ }^{\circ} \mathrm{C}$, and a $95 \% \mathrm{O}_{2} / 5 \% \mathrm{CO}_{2}$ injector was placed in wells, under a differential interference contrast microscope (Leica). Electrophysiology was performed in randomized cultures, in a blinded manner.

\section{Whole-cell patch clamp recordings and intracellular stimulation}

Patch clamp recordings and intracellular stimulation were performed and captured using Multiclamp 700B amplifier (Axon Instruments). Stimulus waveforms were generated using data acquisition software DASYLab11.0 (National Instruments) in Windows computer equipped with National Instruments PCI-MIO-16-E4 board. We used rectangular hyperpolarizing and depolarizing current pulses as stimuli for physiological characterization. Specifically, $350 \mathrm{~ms}$ current pulses starting from $-200 \mathrm{pA}$, were incremented by $10 \mathrm{pA}$. Voltage responses 
were analyzed using software developed by Delphi, 2009, using the following parameters: Resting membrane potential, Resting input resistance, Rheobase, AP Threshold, AP amplitude and duration, AP after hyperpolarization, and the I-O function (gain). The spontaneous excitatory postsynaptic currents (sEPSCs) were recorded in voltage clamp mode at $-70 \mathrm{mV}$ holding potential. The spontaneous inhibitory postsynaptic current (sIPSC) was recorded in voltage clamp mode at $-40 \mathrm{mV}$ holding potential.

\section{Statistical analysis}

Using Prism5 (GraphPad Software Inc, La Jolla, CA), we examined deviations from normality in the data using Kolmogorov-Smirnov test. Slopes were tested using Pearson's correlation coefficient $(\mathrm{r})(\mathrm{p}<0.01)$, and linear regression. The mean of input-output relationship [42] was compared by ANOVA, and Bonferroni's post hoc test $(\mathrm{p}<0.05)$. Individual parameters between controls and Tat $24 \mathrm{~h}$ were compared using Student's t test.

\section{Results}

We examined whether dysfunctional properties are detectable in hippocampal neurons exposed to HIV-1 Tat for 4 and $24 \mathrm{~h}$. We measured electrophysiological properties in the pyramidal subset, in comparison to cultures treated with inactivated Tat. In both time-points, control cultures showed similar behaviors and thus measurements were pooled.

Figure 1 summarizes the parameters characterizing neuronal subsets. Baseline recordings showed that hippocampal neuronal subsets in primary cultures exhibit expected behaviors, and are a valid system for studying the direct effects of HIV peptides such as Tat, or neuroimmune factors. In control cultures, pyramidal Glutamatergic neurons (Fig. 1, red lines) differed from GABAergic interneurons (Fig. 1, blue lines), in recording patterns during whole cell patch-clamp assays. Pyramidal neurons displayed characteristic voltage sag during hyperpolarizing pulse, and strong adaptation (Fig. 1a, upper trace), while interneurons fired at higher frequency
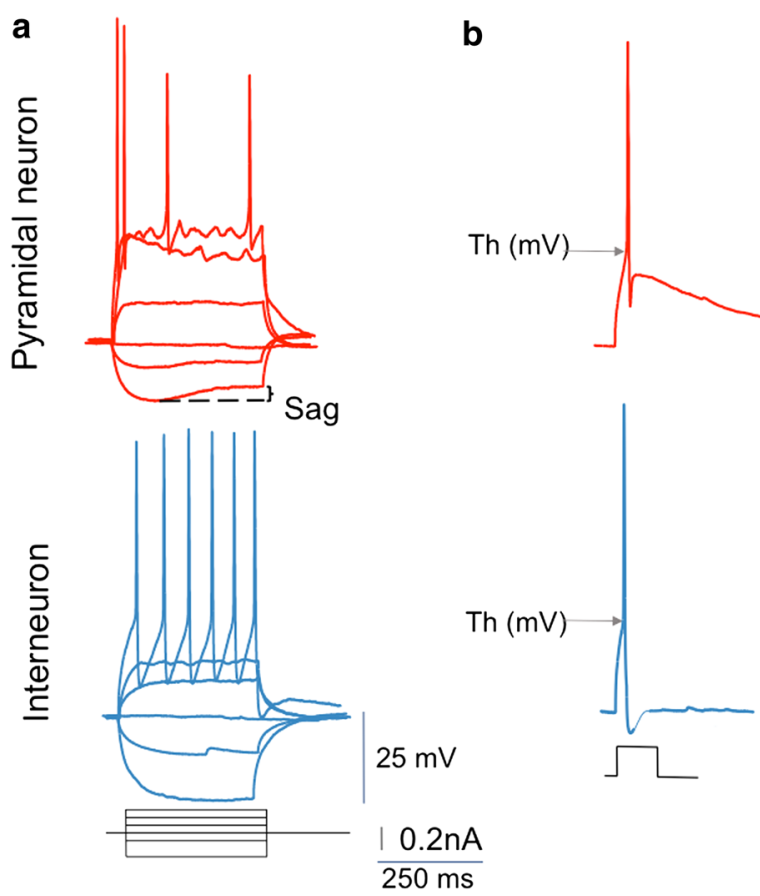

C

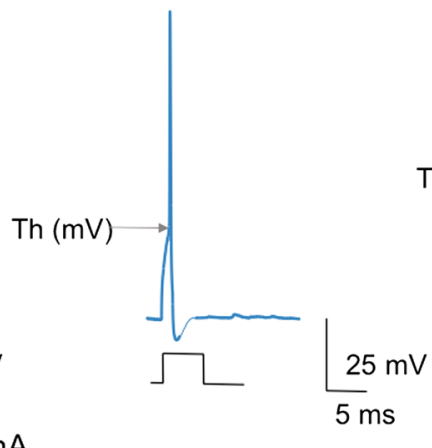

$25 \mathrm{mV}$

$5 \mathrm{~ms}$

AHP

Fig. 1 Summary of baseline electrophysiological function behaviors that distinguish neuronal subsets in hippocampal primary cultures, and that were utilized to examine the effect of Tat exposure. The expected recording profiles distinguish pyramidal glutamatergic neurons (red lines) from GABAergic interneurons (blue lines), as seen in this representative electrophysiological characterization of hippocampal neurons in culture. a Whole cell patch-clamp recording from pyramidal neuron (upper red traces) and interneuron (lower blue traces). Voltage responses to hyperpolarizing and depolarizing current pulses differ in the 2 types of neurons. Pyramidal neurons show their characteristic voltage sag during hyperpolarizing pulse, and a strong adaptation. In contrast, interneurons fire at higher frequency without signs of adaptation. b Action potentials (AP) evoked by a short depolarizing current pulse. In the pyramidal neurons, AP shows a depolarizing potential during the repolarization phase (upper trace). In interneurons, the AP is followed by a fast hyperpolarization, referred to as fast after-hyperpolarization (fAHP) (lower trace), which is a characteristic oh hippocampal interneurons. c The action potential width is shorter in interneurons (blue lines) when compared to pyramidal neurons (res lines). We tested the hypothesis that HIV Tat has the ability to interact with neurons affecting their performance, which can be detectable by changes (increase or decrease) in the pulse current intensity that is necessary to elicit an AP 
without signs of adaptation (Fig. 1a, lower trace). Regarding AP evoked by a short depolarizing current pulse, pyramidal neurons showed depolarizing potential during the repolarization phase (Fig. 1b, upper trace), while in interneurons, AP was followed by a fast after-hyperpolarization (fAHP) (Fig. 1b, lower trace). The AP width was shorter in interneurons (Fig. 1c, blue line) compared to pyramidal neurons (Fig. 1c, red line). All parameters were according to predicted results for these subsets.

Using this system, we tested the hypothesis that Tat can directly affect neuronal performance, detectable by increase or decrease in pulse current intensity necessary to elicit an AP. We have focused on glutamatergic pyramidal neurons, due to their excitatory role in circuitry architecture, and due to their consistent pattern of Tatelicited changes, compared to control neurons. All cultures showed a linear relationship between the injected current and the number of spikes, determined by Pearson's coefficient (Control $\mathrm{r}^{2}=0.9969, \mathrm{p}=0.0031$; Tat $4 \mathrm{~h}$ $\mathrm{r}^{2}=0.9989, \mathrm{p}=0.0011$; Tat 24 $\left.\mathrm{h} \mathrm{r}^{2}=0.9827, \mathrm{p}=0.0004\right)$. Compared to control cultures, Tat did not alter neuronal behaviors at $4 \mathrm{~h}$. However, a strong increase of the gain function was seen at $24 \mathrm{~h}$ (Fig. 2). The slope comparison by linear regression revealed a significant difference, with $\mathrm{F}=16.4446, \mathrm{DFn}=2, \mathrm{DFd}=8$, and $\mathrm{p}=0.001465$, and with a $0.15 \%$ chance of randomly choosing data points exhibiting these differences. The comparison of the mean of the slopes input-output $(\mathrm{I} / \mathrm{O})$ relationship within the tested interval showed a significant difference between Control and Tat $24 \mathrm{~h}(\mathrm{p}=0.002$, Bonferroni's $\mathrm{p}<0.05)$. Yet, pyramidal neurons treated with Tat did not alter the RMP, input resistance, rheobase (or the minimal depolarizing current input that generates an $\mathrm{AP}$ ), and AP threshold at $24 \mathrm{~h}$ (Table 1$)$.

\section{Discussion}

We found that Tat critically affects neuronal intrinsic excitability in cultured hippocampal pyramidal neurons, as a result of a lower reactive threshold to current. This effect was not observed at $4 \mathrm{~h}$ after HIV-1 Tat exposure, but only at the $24 \mathrm{~h}$ time point.

In cell line studies, conflicting results relate to the diversity of models. In a neuro-epithelial-like stem (NES) cell line from human fetal hindbrain, Tat at 10 times lower doses than in our study caused deep changes in gene expression and cytoskeletal structure at $24 \mathrm{~h}$, and a reduction of output excitability at $48 \mathrm{~h}$ [40], likely due to neurotoxicity.

In primary cultures, Tat-induced changes are subset, dose and time-depend. For instance, in rat dorsal root
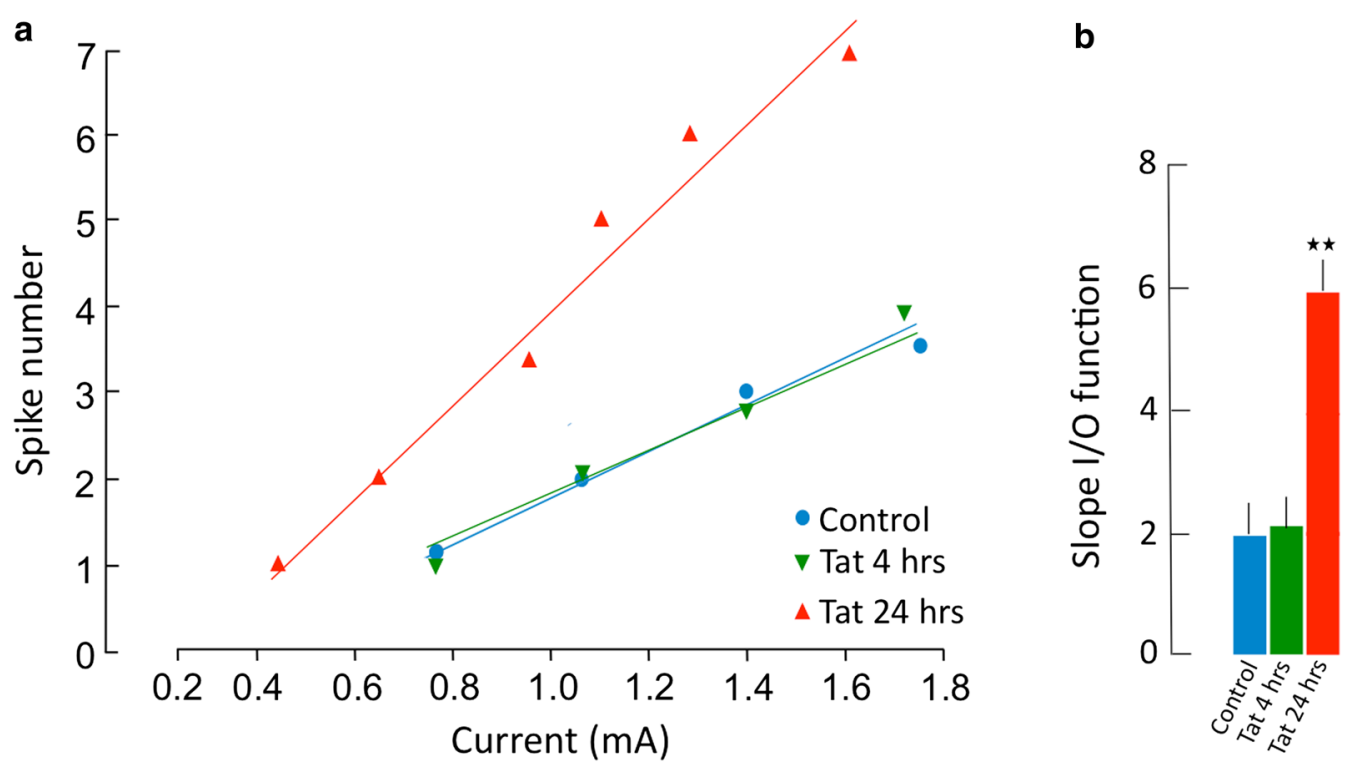

Fig. 2 Input/output function slope (gain) is enhanced in Tat-treated pyramidal neurons. a The graph shows the mean number of action potentials (AP) generated by the pyramidal neurons is response to depolarizing current pulses of different intensities, in one representative experiment. In a defined range of current intensities, the relationship between number of spikes and current intensity is linear. The slope of this function, referred to as "Gain", is higher in the pyramidal neurons treated wit Tat for $24 \mathrm{~h}$ (red), when compared to the control (blue) or to Tat for $4 \mathrm{~h}$ (green) in pyramidal neurons in culture, as determined by Pearson's correlation coefficient. b The bar graph shows the mean ( \pm SEM) slope of the input/ output $(I / O)$ function of controls $(n=10$, blue bar) and Tat treated neurons for $4 \mathrm{~h}(\mathrm{n}=5$, green bar) or for $24 \mathrm{~h}(\mathrm{n}=5$, red bar). The mean slope of the l/O function was $1.95 \pm 0.53$ (SEM) for untreated pyramidal neurons and $5.89 \pm 0.59$ (SEM) for Tat treated neurons ( $p<0.002$, ANOVA followed by Bonferroni's test) 
Table 1 Effect of HIV-1 Tat peptide on resting membrane potential (RMP), input resistance (Rin), action potential threshold, and rheobase in hippocampal pyramidal neurons

\begin{tabular}{llllll}
\hline & RMP $(\mathbf{m V})$ & Rin $(\mathbf{M W})$ & Threshold $(\mathbf{m V})$ & Rheobase $(\mathbf{n A})$ & Gain $(\mathbf{S p i k e /})$ \\
\hline Control & $68.52 \pm 0.33$ & $53.06 \pm 0.889$ & $43.36 \pm 0.201$ & $0.33 \pm 0.071$ & $1.9 \pm 0.7$ \\
HIV-1 Tat 24 & $68.56 \pm 0.63$ & $53.04 \pm 1.12$ & $43.7 \pm 0.466$ & $0.31 \pm 0.032$ & $5.9 \pm 0.6$ \\
t test & 0.956 & 0.989 & 0.522 & 0.543 & $1.678 E-10^{* *}$ \\
\hline
\end{tabular}

The Tat peptide was added to the cultures, and electrophysiological parameters were tested at $24 \mathrm{~h}$

ganglion small diameter capsaicin-sensory neurons, Tat at $20 \mathrm{nM}$ greatly enhanced excitability, suggesting a direct role in pain [43]. On the other hand, studies in rat hippocampal neurons show Tat-induced biphasic changes in NMDA-evoked increases in intracellular $\mathrm{Ca}^{2+}$, with consequences to spontaneous activity [42, 44]. Tat (at 5 -fold higher concentrations than in our study) acutely reduced spontaneous spike frequencies while increasing AP bursts amplitude and duration, followed by attenuation, and adaptation at $24 \mathrm{~h}$. These changes were hypothesized to result from aberrant network activity, attributed to changes in NMDA-gated intracellular $\mathrm{Ca}^{2+}$, mediated by Src kinase and NO signaling $[42,45]$. Our results complement those, suggesting that neuronal adaptability to lower Tat concentrations may be relative, or not applicable to all aspects of neuronal function. Our findings are in agreement with the excitatory effect of Tat on cultured human fetal neurons, and rat hippocampal slices [46-48].

The neuronal ability to receive and transmit information depends on neurotransmitter concentrations in presynaptic terminals, numbers and intrinsic properties of postsynaptic receptors on dendritic trees, and receiving synaptic inputs, which depend on the type of voltagedependent membrane ionic channels. These channels, upon inputs and AP, allow ionic movement, changing the excitability. We observed that Tat increases neuronal excitability, or the slope of the input-output relationship. Tat may enhance firing via $\mathrm{Ca}^{2+}$ influx $[49,50]$, by prolonging $\mathrm{Ca}^{2+}$ potentials mediated by L-channels. Importantly, neuronal voltage-gated $\mathrm{K}+$ channels $(\mathrm{Kv})$ are involved in memory processes [51, 52], and in acquired neuronal channelopathies observed in HIV-associated neurocognitive disorders [53]. Further studies must determine what conductance is affected by Tat exposure, and whether these findings apply to neuroHIV models in vivo. If so, these may have consequences to how HIV in the brain affects perception, reactivity to sensory stimulation, and memory, in part explaining HIV-associated neurobehavioral changes.

\section{Conclusions}

HIV-Tat acts on hippocampal pyramidal neurons by lowering the current pulse intensity threshold that elicits an action potential response, and increases gain slope $24 \mathrm{~h}$ following exposure, indicating an enhanced intrinsic neuronal excitability.

\section{Limitations}

This study was in isolated neurons in culture, not subjected to neuroimmune changes, or active infection, differing from the HIV-infected brain. Yet, it is a system for the examination of direct effects of HIV and its peptides, and that can accommodate complexities from neuroimmune cells. More studies are need for identifying mechanisms by which Tat affects excitability, without affecting other functions.

\section{Abbreviations}

Tat: trans-activator of Transcription; CNS: central Nervous System; P18: prenatal day 18; NO: nitric oxide; HIV: human immunodeficiency virus; HAND: HIVassociated neurocognitive disorders; CA1: cornu ammonis layer 1; AP: action potential; RPM: resting membrane potential; IA: A-type voltage gated channel; Id: delayed rectifier $\mathrm{K}+$ gated channel; IKCa: L-type voltage-gated $\mathrm{Ca}^{2+}$ channel; GCaS: voltage-gated $\mathrm{Ca}^{2+}$ channel conductance; Ih: inward channel; I-O: input: output; DC: direct current; Hr: hour; Hrs: hours; E17: embryonic day 17; HEPES: 4-(2-hydroxyethyl)-1-piperazineethanesulfonic acid; HBSS: Hank's balanced salt solution; SDBRI: San Diego Biomedical Research Institute; TSRI: The Scripps Research Institute; DMEM: Dulbecco's modified Eagle's medium; AIDS: acquired immunodeficiency syndrome; pA: pico-amperes; $\mathrm{mS}$ : millisecond; SIPSC: inhibitory post synaptic current; $\mathrm{mV}$ : millivolts; ANOVA: analysis of variance; fAHP: fast after hyperpolarization; NES: neuro-epithelial-like stem cell; NMDA: N-methyl-D-aspartate; Kv: voltage-gated K+ channels.

\section{Authors' contributions}

MCGM: study concept and design, data analysis and interpretation, manuscript writing, editing and submission; WF and FB: study concept and design, performance of electrophysiology techniques, data analysis and interpretation, manuscript writing. All authors read and approved the final manuscript.

\section{Author details \\ ${ }^{1}$ San Diego Biomedical Research Institute, 10865 Road to the Cure, San Diego, CA 92121, USA. ${ }^{2}$ Department of Anatomy and Cell Biology, College of Medicine, University of Illinois Chicago, 6068 COMRB MC 512, Chicago, IL 60612, USA. ${ }^{3}$ The Scripps Research Institute, 10550 North Torrey Pines Rd., La Jolla, CA 92037, USA}

\section{Acknowledgements}

The authors wish to thank Dr. Sandra Encalada, The Scripps Research Institute, La Jolla, CA, for providing the neuronal cultures used in this study, and Dr. Bruno Conti for the space and amazing support. We also thank Daniel Ryan (SDBRI) for critically reviewing our manuscript.

\section{Competing interests}

The authors declare that they have no competing of interests. 


\section{Availability of data and materials}

Data are all contained within the paper. The datasets from the analyses are available from the corresponding author on reasonable request.

\section{Consent for publication}

Not applicable.

\section{Ethics approval and consent to participate}

All animal use was reviewed and approved by the Institutional Animal Care and Use Committee of The Scripps Research Institute and of the San Diego Biomedical Research Institute.

\section{Funding}

The authors declare that this experiment was partially funded by the R01DA036164 to MCGM

\section{Publisher's Note}

Springer Nature remains neutral with regard to jurisdictional claims in published maps and institutional affiliations.

Received: 15 November 2017 Accepted: 21 April 2018

Published online: 04 May 2018

\section{References}

1. Barreto GE, Gonzalez J, Torres Y, Morales L. Astrocytic-neuronal crosstalk: implications for neuroprotection from brain injury. Neurosci Res. 2011:71(2):107-13.

2. Bechade C, Cantaut-Belarif Y, Bessis A. Microglial control of neuronal activity. Front Cell Neurosci. 2013;7:32.

3. Bessis A, Bechade C, Bernard D, Roumier A. Microglial control of neuronal death and synaptic properties. Glia. 2007;55(3):233-8

4. Dalmau I, Finsen B, Tonder N, Zimmer J, Gonzalez B, Castellano B. Development of microglia in the prenatal rat hippocampus. J Comp Neurol. 1997;377(1):70-84.

5. Dalmau I, Finsen B, Zimmer J, Gonzalez B, Castellano B. Development of microglia in the postnatal rat hippocampus. Hippocampus. 1998:8(5):458-74.

6. Dalmau I, Vela JM, Gonzalez B, Finsen B, Castellano B. Dynamics of microglia in the developing rat brain. J Comp Neurol. 2003;458(2):144-57.

7. Elkabes S, DiCicco-Bloom EM, Black IB. Brain microglia/macrophage express neurotrophins that selectively regulate microglial proliferation and function. J Neurosci. 1996;16(8):2508-21.

8. Hanisch UK. Microglia as a source and target of cytokines. Glia. 2002:40(2):140-55.

9. Barger SW, Basile AS. Activation of microglia by secreted amyloid precursor protein evokes release of glutamate by cystine exchange and attenuates synaptic function. J Neurochem. 2001;76(3):846-54.

10. Chao CC, Hu S, Molitor TW, Shaskan EG, Peterson PK. Activated microglia mediate neuronal cell injury via a nitric oxide mechanism. J Immunol. 1992;149(8):2736-41.

11. Floden AM, Li S, Combs CK. Beta-amyloid-stimulated microglia induce neuron death via synergistic stimulation of tumor necrosis factor alpha and NMDA receptors. J Neurosci. 2005;25(10):2566-75.

12. Piani D, Frei K, Do KQ, Cuenod M, Fontana A. Murine brain macrophages induced NMDA receptor mediated neurotoxicity in vitro by secreting glutamate. Neurosci Lett. 1991;133(2):159-62.

13. An SF, Groves M, Gray F, Scaravilli F. Early entry and widespread cellular involvement of HIV-1 DNA in brains of HIV-1 positive asymptomatic individuals. J Neuropathol Exp Neurol. 1999;58(11):1156-62.

14. Burdo TH, Lo J, Abbara S, Wei J, DeLelys ME, Preffer F, Rosenberg ES, Williams KC, Grinspoon S. Soluble CD163, a novel marker of activated macrophages, is elevated and associated with noncalcified coronary plaque in HIV-infected patients. J Infect Dis. 2011;204(8):1227-36.

15. Debaisieux S, Rayne F, Yezid H, Beaumelle B. The ins and outs of HIV-1 Tat. Traffic. 2012;13(3):355-63.

16. Rayne F, Debaisieux S, Bonhoure A, Beaumelle B. HIV-1 Tat is unconventionally secreted through the plasma membrane. Cell Biol Int. 2010;34(4):409-13.
17. Rayne F, Debaisieux S, Tu A, Chopard C, Tryoen-Toth P, Beaumelle B. Detecting HIV-1 Tat in cell culture supernatants by ELISA or Western Blot. Methods Mol Biol. 2016:1354:329-42.

18. Vendeville A, Rayne F, Bonhoure A, Bettache N, Montcourrier P, Beaumelle B. HIV-1 Tat enters T cells using coated pits before translocating from acidified endosomes and eliciting biological responses. Mol Biol Cell. 2004;15(5):2347-60.

19. Carey AN, Liu X, Mintzopoulos D, Paris JJ, Muschamp JW, McLaughlin JP, Kaufman MJ. Conditional Tat protein expression in the GT-tg bigenic mouse brain induces gray matter density reductions. Prog Neuropsychopharmacol Biol Psychiatry. 2013;43:49-54.

20. Carey AN, Sypek El, Singh HD, Kaufman MJ, McLaughlin JP. Expression of HIV-Tat protein is associated with learning and memory deficits in the mouse. Behav Brain Res. 2012;229(1):48-56.

21. Pettit DL, Augustine GJ. Distribution of functional glutamate and GABA receptors on hippocampal pyramidal cells and interneurons. J Neurophysiol. 2000;84(1):28-38

22. Lisman JE. Bursts as a unit of neural information: making unreliable synapses reliable. Trends Neurosci. 1997;20(1):38-43.

23. Williams SR, Stuart GJ. Mechanisms and consequences of action potential burst firing in rat neocortical pyramidal neurons. J Physiol. 1999;521(Pt 2):467-82.

24. Epsztein J, Brecht M, Lee AK. Intracellular determinants of hippocampal CA1 place and silent cell activity in a novel environment. Neuron. 2011;70(1):109-20

25. Golding NL, Staff NP, Spruston N. Dendritic spikes as a mechanism for cooperative long-term potentiation. Nature. 2002:418(6895):326-31.

26. Moscovitch M, Nadel L, Winocur G, Gilboa A, Rosenbaum RS. The cognitive neuroscience of remote episodic, semantic and spatial memory. Curr Opin Neurobiol. 2006;16(2):179-90.

27. Castelo JM, Sherman SJ, Courtney MG, Melrose RJ, Stern CE. Altered hippocampal-prefrontal activation in HIV patients during episodic memory encoding. Neurology. 2006;66(11):1688-95.

28. Winocur G, Moscovitch M, Rosenbaum RS, Sekeres M. A study of remote spatial memory in aged rats. Neurobiol Aging. 2010;31(1):143-50.

29. Behnisch T, Francesconi W, Sanna PP. HIV secreted protein Tat prevents long-term potentiation in the hippocampal CA1 region. Brain Res. 2004:1012(1-2):187-9.

30. Silver RA. Neuronal arithmetic. Nat Rev Neurosci. 2010;11(7):474-89.

31. Disterhoft JF, Oh MM. Learning, aging and intrinsic neuronal plasticity. Trends Neurosci. 2006;29(10):587-99.

32. Disterhoft JF, Oh MM. Pharmacological and molecular enhancement of learning in aging and Alzheimer's disease. J physiol Paris. 2006;99(2-3):180-92.

33. Disterhoft JF, Oh MM. Alterations in intrinsic neuronal excitability during normal aging. Aging Cell. 2007;6(3):327-36.

34. Kim JR, Ahn SY, Jeong SW, Kim LS, Park JS, Chung SH, Oh MK. Cortical auditory evoked potential in aging: effects of stimulus intensity and noise. Otol Neurotol. 2012;33(7):1105-12.

35. Oh MM, Disterhoft JF. Cellular mechanisms for altered learning in aging Future neurology. 2010:5(1):147-55.

36. Oh MM, Oliveira FA, Disterhoft JF. Learning and aging related changes in intrinsic neuronal excitability. Front Aging Neurosci. 2010;2:2.

37. Szucs A, Berton F, Sanna PP, Francesconi W. Excitability of jcBNST neurons is reduced in alcohol-dependent animals during protracted alcohol withdrawal. PLoS ONE. 2012;7(8):e42313.

38. Tryoen-Toth P, Chasserot-Golaz S, Tu A, Gherib P, Bader MF, Beaumelle B, Vitale N. HIV-1 Tat protein inhibits neurosecretion by binding to phos phatidylinositol 4,5-bisphosphate. J Cell Sci. 2013;126(Pt 2):454-63.

39. Ganief T, Gqamana P, Garnett S, Hoare J, Stein DJ, Joska J, Soares N, Blackburn JM. Quantitative proteomic analysis of HIV-1 Tat-induced dysregulation in SH-SY5Y neuroblastoma cells. Proteomics. 2017:17(6):1600236.

40. Gurwitz KT, Burman RJ, Murugan BD, Garnett S, Ganief T, Soares NC, Raimondo JV, Blackburn JM. Time-dependent, HIV-Tat-induced perturbation of human neurons in vitro: towards a model for the molecular pathology of HIV-associated neurocognitive disorders. Front Mol Neurosci. 2017;10:163.

41. Falzone TL, Stokin GB, Lillo C, Rodrigues EM, Westerman EL, Williams DS, Goldstein LS. Axonal stress kinase activation and tau misbehavior induced by kinesin-1 transport defects. J Neurosci. 2009;29(18):5758-67. 
42. Krogh KA, Wydeven N, Wickman K, Thayer SA. HIV-1 protein Tat produces biphasic changes in NMDA-evoked increases in intracellular $\mathrm{Ca}_{2}{ }^{+}$concentration via activation of $\mathrm{Src}$ kinase and nitric oxide signaling pathways. J Neurochem. 2014;130(5):642-56.

43. Chi X, Amet T, Byrd D, Chang KH, Shah K, Hu N, Grantham A, Hu S, Duan J, Tao F, et al. Direct effects of HIV-1 Tat on excitability and survival of primary dorsal root ganglion neurons: possible contribution to HIV1-associated pain. PLoS ONE. 2011;6(9):e24412.

44. Krogh KA, Green MV, Thayer SA. HIV-1 Tat-induced changes in synaptically-driven network activity adapt during prolonged exposure. Curr HIV Res. 2015;12(6):406-14.

45. Krogh KA, Green MV, Thayer SA. HIV-1 Tat-induced changes in synaptically-driven network activity adapt during prolonged exposure. Curr HIV Res. 2014;12(6):406-14.

46. Cheng J, Nath A, Knudsen B, Hochman S, Geiger JD, Ma M, Magnuson DS. Neuronal excitatory properties of human immunodeficiency virus type 1 Tat protein. Neuroscience. 1998;82(1):97-106.

47. Magnuson DS, Knudsen BE, Geiger JD, Brownstone RM, Nath A. Human immunodeficiency virus type 1 tat activates non- $N$-methyl-D-aspartate excitatory amino acid receptors and causes neurotoxicity. Ann Neurol. 1995;37(3):373-80.
48. Nath A, Psooy K, Martin C, Knudsen B, Magnuson DS, Haughey N, Geiger JD. Identification of a human immunodeficiency virus type 1 Tat epitope that is neuroexcitatory and neurotoxic. JVirol. 1996;70(3):1475-80.

49. Brailoiu GC, Brailoiu E, Chang JK, Dun NJ. Excitatory effects of human immunodeficiency virus 1 Tat on cultured rat cerebral cortical neurons. Neuroscience. 2008;151(3):701-10.

50. Napier TC, Chen L, Kashanchi F, Hu XT. Repeated cocaine treatment enhances HIV-1 Tat-induced cortical excitability via over-activation of -type calcium channels. J Neuroimmune Pharmacol. 2014;9(3):354-68.

51. Giese KP, Storm JF, Reuter D, Fedorov NB, Shao LR, Leicher T, Pongs O, Silva AJ. Reduced K+ channel inactivation, spike broadening, and after-hyperpolarization in Kvbeta1.1-deficient mice with impaired learning. Learn Mem. 1998;5(4-5):257-73.

52. Solntseva El, Bukanova luV, Skrebitskii VG. Memory and potassium channels. Usp Fiziol Nauk. 2003;34(4):16-25.

53. Gelman BB, Soukup VM, Schuenke KW, Keherly MJ, Holzer C 3rd, Richey FJ, Lahart CJ. Acquired neuronal channelopathies in HIV-associated dementia. J Neuroimmunol. 2004;157(1-2):111-9.
Ready to submit your research? Choose BMC and benefit from:

- fast, convenient online submission

- thorough peer review by experienced researchers in your field

- rapid publication on acceptance

- support for research data, including large and complex data types

- gold Open Access which fosters wider collaboration and increased citations

- maximum visibility for your research: over 100M website views per year

At BMC, research is always in progress.

Learn more biomedcentral.com/submissions 